\title{
Digital Earth: Prism of 2020
}

\author{
Eugene Eremchenko ${ }^{1}$ \\ ${ }^{1}$ Lomonosov Moscow State University, GSP-1, Moscow, 119991, Russia
}

\begin{abstract}
Through the prism of the 8th Digital Earth Summit and within the context of the disastrous 2020, this article addresses some of the issues and challenges that need to be addressed in Digital Earth Vision 2030. Some significant scientific aspects of the Digital Earth development are described and briefly discussed: the problem of providing a satisfactory definition of the Digital Earth and typology of different geospatial visualizations, the ambiguity between the concepts of Digital Earth and Digital Twins, the problems arising from the use of Digital Earth in sustainable development as well as the problem of using Digital Earth for natural and technological disasters prevention and mitigation. Attention is given to the use of Digital Earth in exploring the key challenge of 2020 - the COVID-19 pandemic. The possibility of using the Digital Earth as a tool for fundamental research is declared.
\end{abstract}

\section{Keywords}

Digital Earth, Digital Twins, sustainable development, COVID-19, global governance

\section{Introduction}

2020 was a pivotal year in the history of Digital Earth as the Digital Earth Vision 2020 agenda [1], the ten-year development framework established by the International Society for Digital Earth (ISDE), was finalized, and the preparation of a new document for the period up to 2030 was started. The following research must consider the changing scientific, technological landscape, fast digital transformation and, of course, existed social challenges. Most notable of them is the COVID-19 pandemic that started in 2020, and the resulting global civilization crisis that completely changed our mental horizon. Combining these two factors is cognitively significant as it reveals the prospects of both urban civilization and a current worldview. At the same time, it provides a unique opportunity to address the Digital Earth Vision 2030 with new urgent problems in human development. Therefore, it makes sense to consider the evolution of the Digital Earth concept through the prism of the milestone year 2020 .

In 2020, the main annual ISDE event - the 8th Digital Earth Summit - was held in Russia for the first time in the history. Due to pandemic crisis the Summit was held online - also the first time in ISDE history. Despite all obstacles, it was recognized as a success [2]. According to current preliminary estimates, it was the biggest (by number of countries involved) scientific event in the history of USSR and Russian Federation. The statistics of the 8th Digital Earth Summit are revealing the extent to which Digital Earth ideas are being adapted today. Also the 8th Digital Earth Summit can be used to explore trends in the development of Digital Earth as a new scientific paradigm.

Desperate attempts to respond to the civilisational challenges of 2020 force humankind to focus on Digital Earth. In this situation, it is essential to clarify the current vision of the Digital Earth and approaches to embedding it into the global governance system. Therefore, an analysis of the current challenges and problems unvailed by the Digital Earth becomes necessary.

This review article proposes to discuss some of the milestones and pitfalls of the development and recognition of Digital Earth.

GraphiCon 2021: 31st International Conference on Computer Graphics and Vision, September 27-30, 2021, Nizhny Novgorod, Russia EMAIL: eugene.eremchenko@gmail.com (E. Eremchenko)

ORCID: 0000-0002-4416-7617 (E. Eremchenko)

$\begin{array}{ll}\text { (c) (i) } & \text { (c) } 2021 \text { Copyright for this paper by its authors. } \\ \text { Use permitted under Creative Commons License Attribution } 4.0 \text { International (CC BY 4.0). } \\ \text { CEUR Workshop Proceedings (CEUR-WS.org) }\end{array}$ 


\section{8th Digital Earth Summit: Facts and Figures}

8th Summit of Digital Earth 2020 was held on November, 30 - December, 2 in Protvino (Russia). Due to COVID-19 pandemic and the resulting global restrictions on travel it took place online in cyberspace at site https://DESummit2020.org [3] (Figure 1). The Summit was an interesting and thought-provoking event, reflecting the depth of penetration of the Digital Earth Vision at a time of profound civilization crisis caused by the COVID-19 pandemic. Data on the geospatial distribution of participants is a marker and a potentially useful source for exploring the impact of Digital Earth on global governance.

The summit was organized under the slogan "Digital Earth in a Changed World: Challenges and Opportunities» and consisted of six sessions, two each day, of a duration of 3 hours daily, in total 9 hours. Online sharing of presentations and communication between reporters and attendees was provided with the Cisco Webex Meetings platform provided and maintained by the team from Paris Lodron University of Salzburg (Austria). Summit was free and open for all reporters and attendees.

Despite the special circumstances and the change in format of the Summit, it has attracted great and remarkable interest.

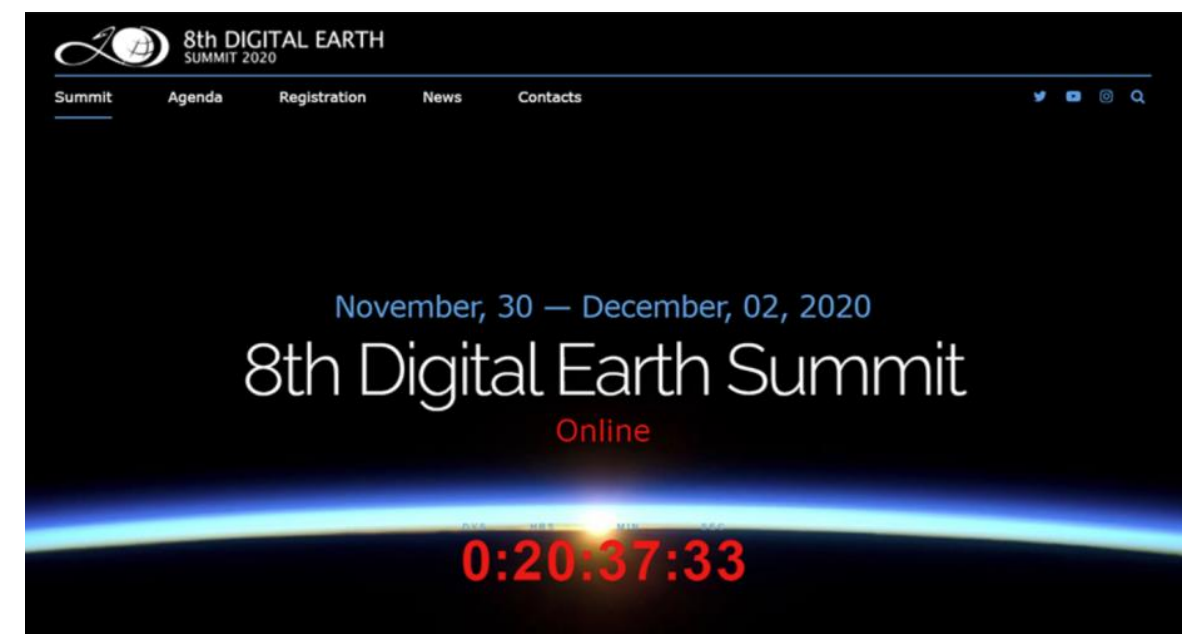

Figure 1: The main page of the 8th Digital Earth Summit 2020 web-site

According to the registration system data, 384 participants registered for the Summit. They represent 77 countries from all five inhabited continents (excluding Antarctica) with $79 \%$ of the world's population and 69\% of the Earth terrestrial (Figure 2); in English alphabet order - from Afghanistan to Venezuela. The most represented (by area of countries) continents are Australia, North America and Eurasia, the least represented - Africa.

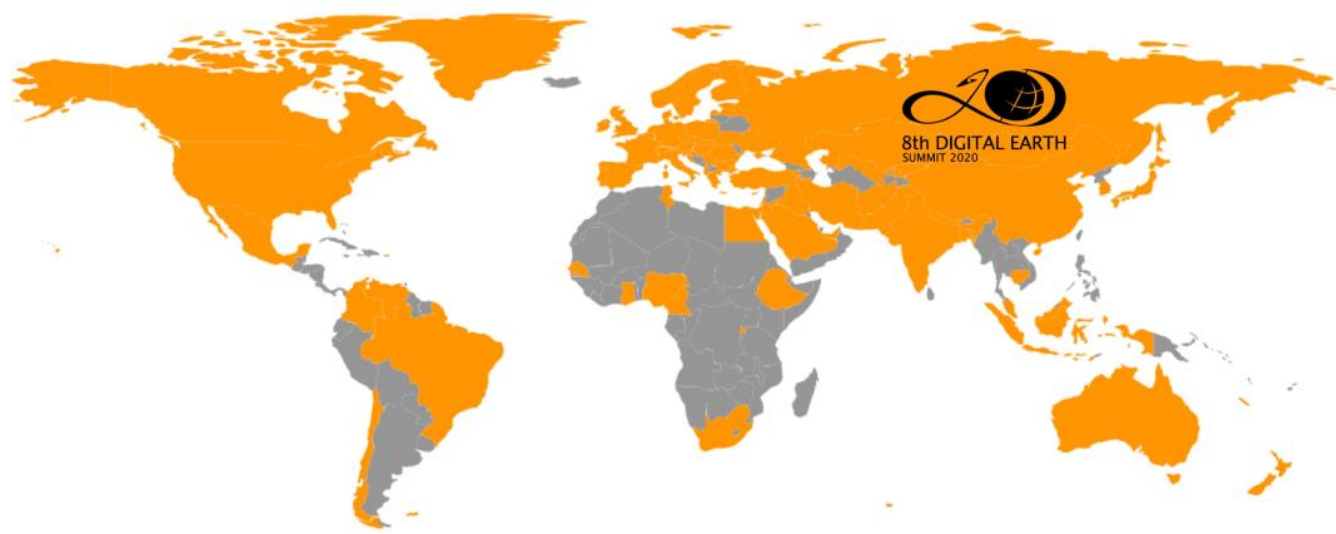


Figure 2: Countries represented on the 8th Digital Earth Summit 2020 by registered participants

The top 10 countries are Russia (40 registered participants), China (35), the United States of America (31), Austria (27), Germany (21), Italy (18), Australia (14), India (14), Netherlands (14), Bulgaria (10). 16 countries were represented by two registrations, 33 countries - by only one (Figure 3 ).

Three areas can be identified in Europe with a relatively low share of registered users compared to neighbouring regions - 1) the United Kingdom and France, 2) Central Balkans, 3) Lithuania/Poland/Belarus/Ukraine/Moldova/Romania (Figure 4). Leaders are Austria (3 registrations per 1 mln. population), Luxembourg (1.6) and Bulgaria (1.4).

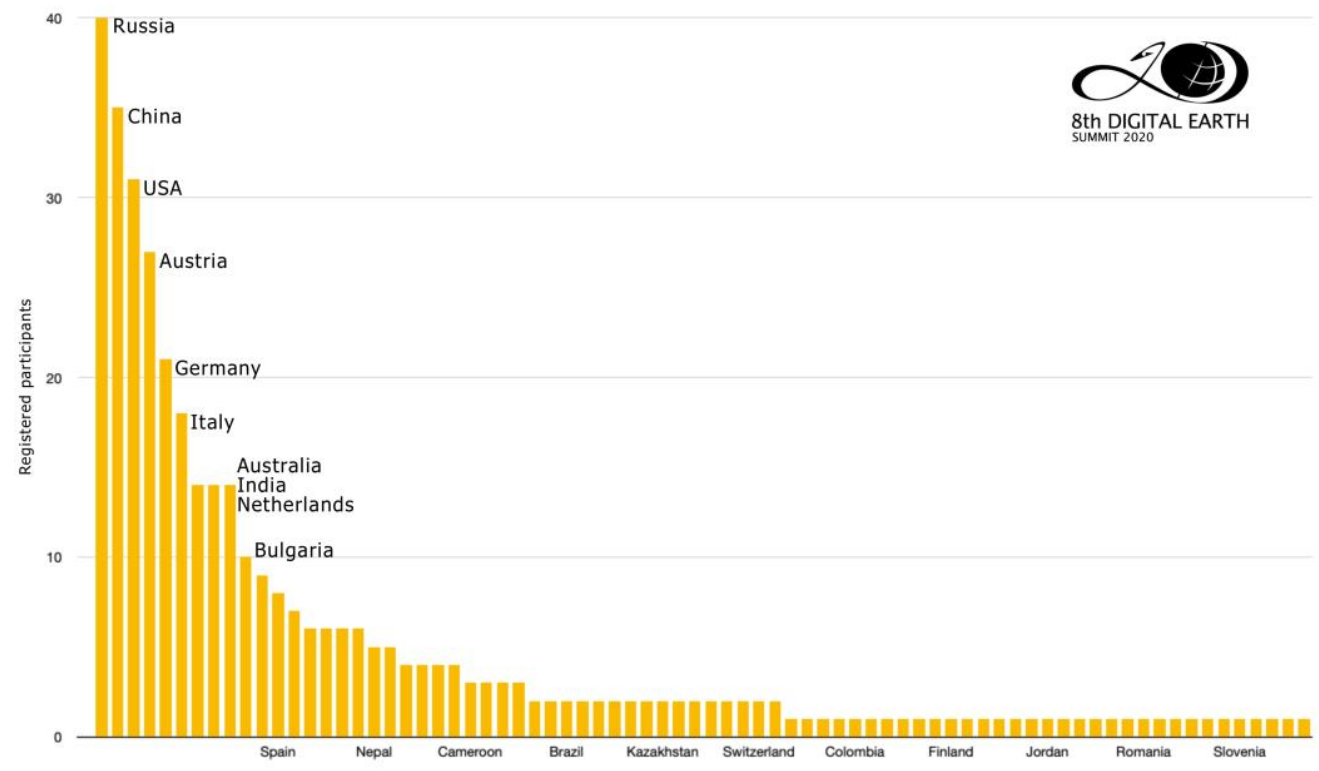

Figure 3: Countries represented on the 8th Digital Earth Summit 2020 by number of the registered participants (histogram)

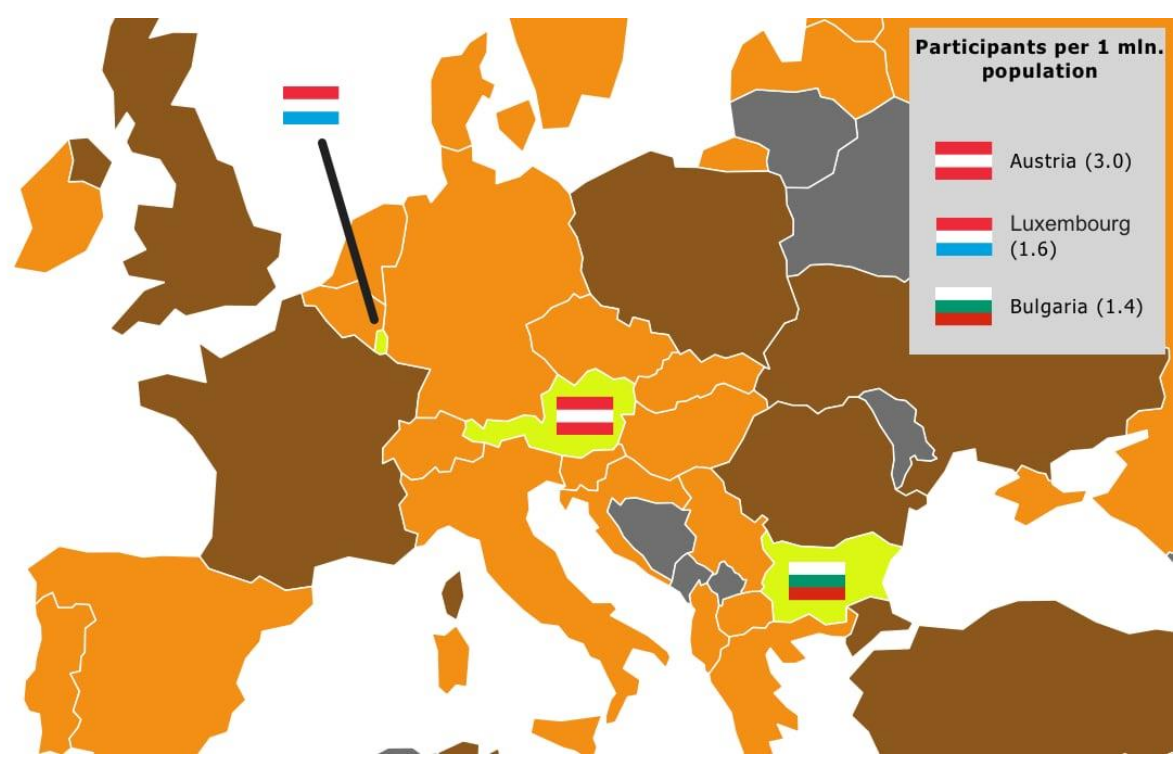

Figure 4: The number of participants per million inhabitants in different European countries. Brighter - better, darker - worse, grey - no registrations at all. Austria, Luxembourg and Bulgaria are the leaders

There were 242 active Summit participants from 58 countries, recognized as attendees, or $63 \%$ of registered users (Figure 5). The leaders (Figure 6) are Austria (23 actual participants), Russia (21), USA 
(19), China (18), Germany (18), Italy (13), Netherlands (9), Australia (8), Bulgaria (8), India (6), Belgium (6) and Greece (6).

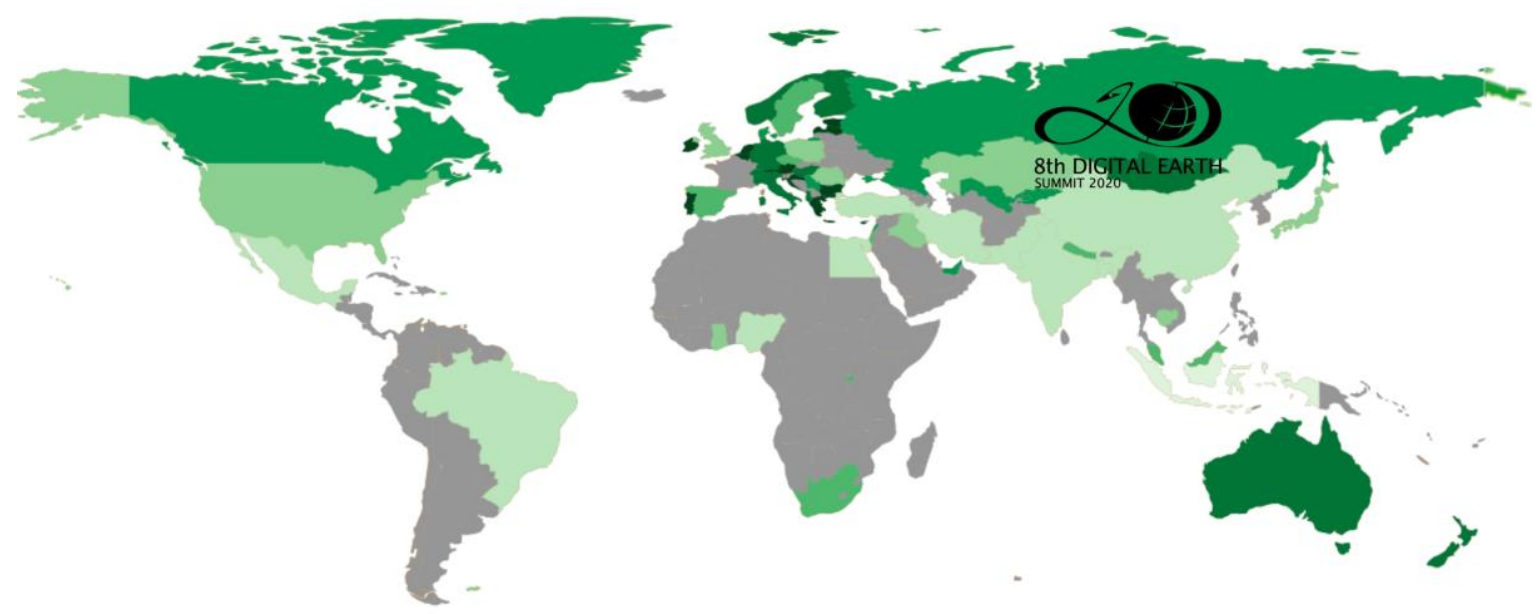

Figure 5: Countries represented on the 8th Digital Earth Summit 2020 by actual attendees and classified according to attendees/population ratio. Dark green - better, light green - worse. Countries shown in grey were not represented at the Summit

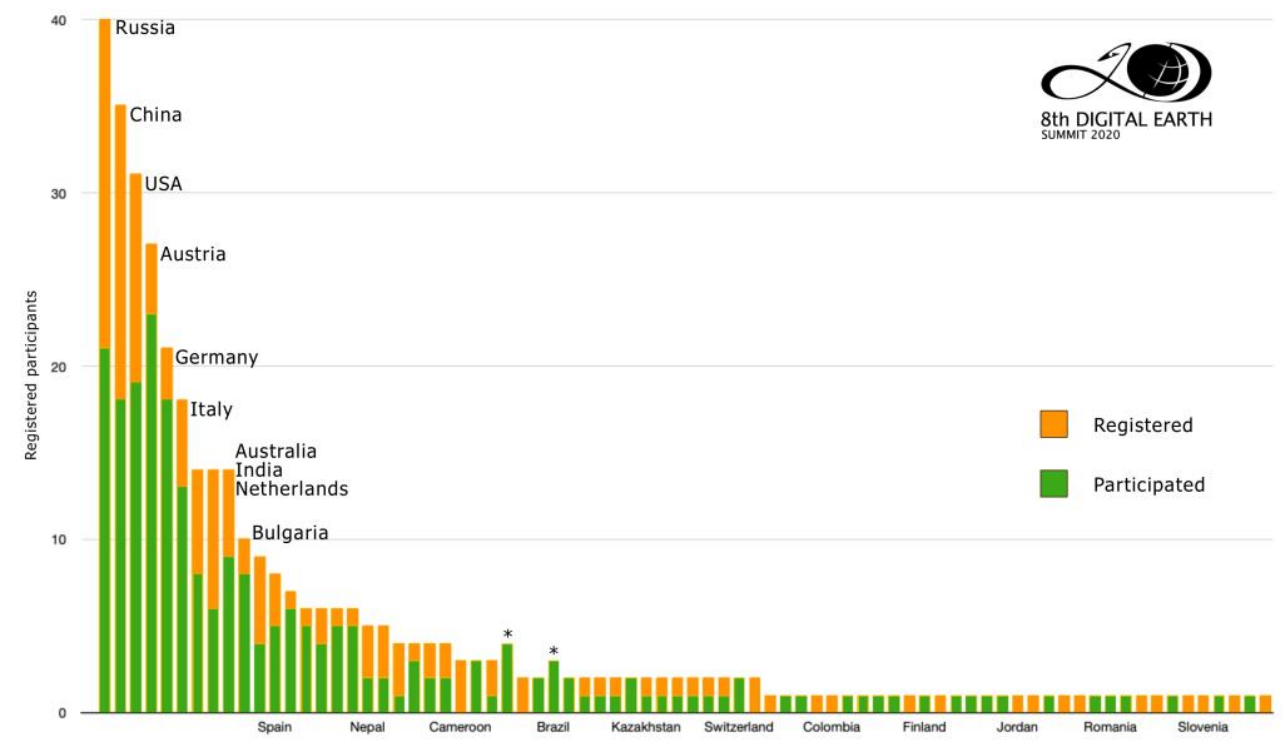

Figure 6: Share of actual participants in the 8 Digital Earth Summit (marked green). Marked $\left({ }^{*}\right)-$ presenters were registered during the session.

During the Summit's 1st day (November, 30), there were 42 chat messages and 15 questions and answers. During the 2nd day (December 1) - 73 chat messages and 42 questions and answers. No data about online activities during the 3rd day of the Summit (December 2). Engagement of the attendees' can be associated with and roughly assessed by the total length of personal user sessions. Length of individual sessions on different days presented in Fig. 7, a. The distribution is relatively flat. The number of individual sessions far exceeds the number of users (on average twice as many), maybe due to speaker needs or technical difficulties. Fig. 7, b. shows a cumulative profile of the number of sessions during the first day (30 November). Webex online conference was also broadcasted online as a video stream through a Facebook social network. The stream was accessible directly on the official site of the Summit. During the 1 st day of the Summit (November 30), there were 1085 contacts and 133 interactions, during the 2nd day (December 1) - 459 contacts and 70 interactions, during the 3rd day (December 2) -575 contacts and 51 interactions (Fig. 8). 

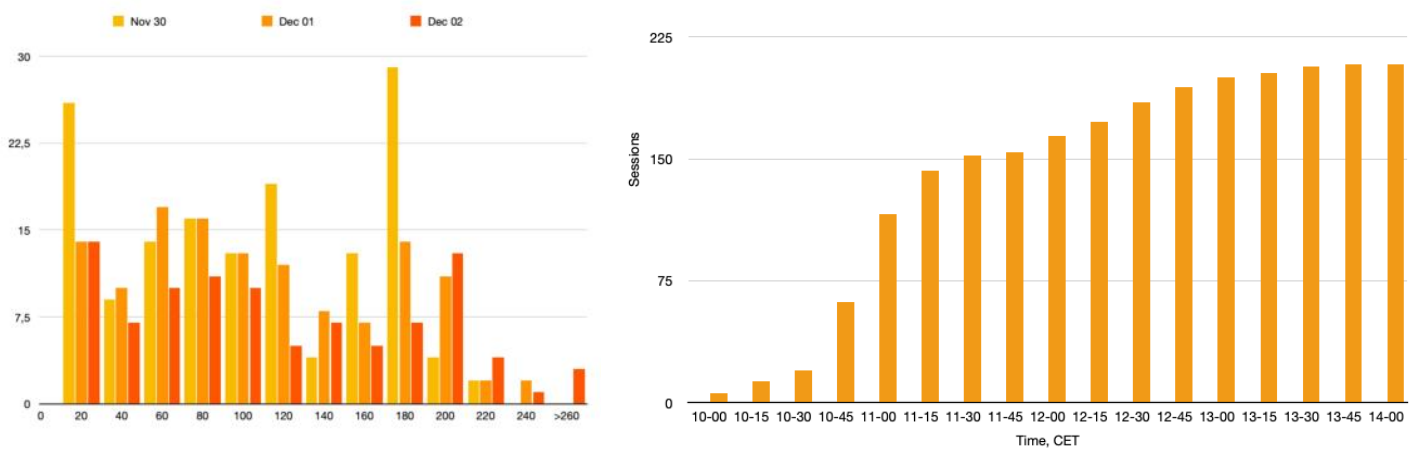

Figure $7(\mathbf{a}, \mathbf{b})$ : Left to right. a) Distribution of the total length of the personalized sessions in minutes during the Summit. b) Number of the individual user sessions during 1st day of the Summit (November, 30)

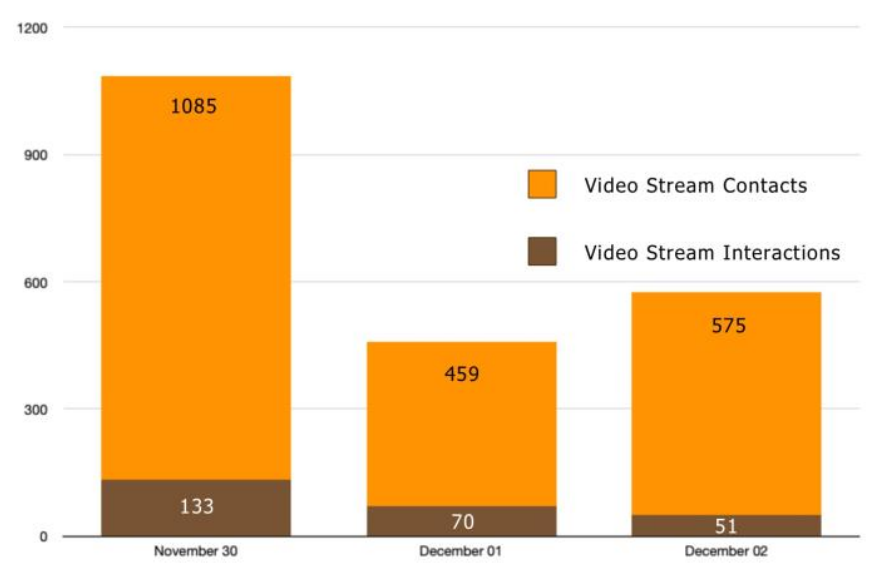

Figure 8: Contacts and interactions with the video stream of the Summit broadcasted through the Facebook social network in addition to attendees of the Summit

\section{Digital Earth Vision: New Challenges of 2020s}

The outcome of the $8^{\text {th }}$ Digital Earth Summit clearly shows that by 2020 the Digital Earth has become a rapidly evolving and adaptable scientific concept. It is amazing that the concept has so broadly embraced intellectual groups from around the world, irrespective of the current state of their economies or their specific cultures. Such rapid development against the backdrop of a hybrid civilization crisis creates both new opportunities for humanity and new threats associated with ad hoc and inappropriate implementation of the new technologies. Under these conditions, the analysis of the existing trends of the Digital Earth development and its scientific origins is of particular importance. Furthermore, the extraordinary events of 2020 and new challenges have qualitatively changed the social and technological landscape and set new directions for the urgent development of Digital Earth. The following should be mentioned as the most pressing challenges for the development of the Digital Earth in the coming decade:

1. Defining the Digital Earth.

2. Understanding the relationship between Digital Earth and Digital Twins.

3. Understanding the links between the sustainable development and the Digital Earth.

4. Digital Earth and the study of the COVID-19 pandemic. Responding to global challenges. 


\subsection{Defining the Digital Earth}

A paradoxical feature of Digital Earth is that its integral definition is still lacking, despite the successful implementation of the concept in 2005 with starting of the Google Earth service and the active adaptation around the world. First definition of the Digital Earth was proposed by its founder Albert Gore first time in 1992 [4]. In 1998 he described the future Digital Earth as a "...a multiresolution, three-dimensional representation of the planet, into which we can embed vast quantities of geo-referenced data"[5].

Later, in 2012, ISDE Council proposed the new, improved definition of the Digital Earth [6]: "Digital Earth makes use of digital technologies to model earth systems, including its cultural and social aspects represented by human societies living on the planet. The model is a multidimensional, multiscale, multitemporal, and multilayered information system. Digital Earth is envisaged as a common platform to support national and international cooperation for global sustainable development, and a newly-developing point of economic growth and social well-being.

The Digital Earth Vision incorporates a digitally-formatted Earth accessible directly through the internet-connected citizens of the planet and supports facilitating data and information provision to others."

Both definitions identify the essence of the Digital Earth as a specific visualization, featuring multiscale and three-dimensional properties. This is correct, but it is only part of the truth; for example, multiscale is not a unique feature of Digital Earth, as it has long been implemented in geographical atlases. On the other hand, both definitions overlook a vital feature of Digital Earth - it provides continuous, non-discrete changing of scale, whereas all maps, including atlases and globes, are essentially discrete and scale-dependent. A new consistent definition should contain criteria for distinguishing Digital Earth among the variety of different geospatial products and serve as a basis for creating their typology. In fact, a scientific stipulative definition [7] of Digital Earth should answer two questions [8]:

1. What is a Digital Earth?

2. What is not a Digital Earth? Which geospatial approaches are beyond of Digital Earth approach?

The rapid development of nowadays and analysis of the existed DE-platforms requires additional clarification of the definition, especially in its scientific origins, due to the ambiguity in the meaning of "digital". In fact, all modern information systems are digital replicas of reality in the narrow computer sense and all scientific theories of all times are without exception "digital" in the semiotic meaning of the word. But these replicas are only simplified representation of reality with their own limits, not true "twins". However, the Digital Earth pretends to be something more - an accurate and consistent, over a wide dynamic range, visual model of the real Earth.

The definition of Digital Earth has yet to be worked out. At this point, there are clear evidences that "digital" is not the essence of Digital Earth. Understanding the vital and key features of the Digital Earth is the main intrigue of the current phase of development of the concept.

\subsection{Digital Earth and Digital Twins}

"Digital Twins" concept is one of the most actively promoted Digital Earth's "rivals" today. Digital Earth and Digital Twins are "twins" indeed, since they were coined almost simultaneously, on a wave of positive expectations from digitalization in 1992 and 1991 [9] respectively, and then conceptualized in 1998 and 2002 [10] respectively. But the relationship between these two "digital" concepts needs careful consideration as it raises some fundamental questions.

In the beginning, Digital Twins were seen in an "industrial" style as a summa of products, technical systems or technological processes, their digital replicas, and relationships between them. However, in the framework of the Internet of Things (IoT), the idea of the possibility and feasibility of an integral digital copy of the entire planet was worked out: "In the future, it might be possible to connect (in the virtual world) diverse digital twins representing extremely complex and vast domains, such as natural 
phenomena and social processes. Virtual forms of future digital twins might even be developed to model the Earth domain, a digital twin of our planet, or Earth twin". [11].

The duality of the meaning of the term Digital Twin has been highlighted in [12]. The initial definition of Digital Twin as "a mirror image of a physical process that is articulated alongside the process in question, usually matching exactly the operation of the physical process that takes place in real time" does not equal its modern, broader definition as a "variety of digital simulation models that run alongside real-time processes that pertain to social and economic systems as well as physical systems". Digital Twin as a complete "mirror" of a real-world system could not be achieved in most cases. Moreover, the assumption of the possibility of creating such a copy generates internal contradictions. At the same time, the creation of models i.e. simplified versions of real-world systems, is certainly possible, but the applicability boundaries of such models in the analysis of real-world processes dynamics are narrow, and the more complex a system is, the more limited is the possibility of its Digital Twin creation. The creation of a complete information twin of a system is possible only if a comprehensive theoretical model exists - this applies only to some elementary abstract systems. For example, it is possible to create a complete Digital Twin system out of two celestial bodies controlled by gravity only. At the same time, it is impossible, for example, to create a model of a living being (there is not even a scientific definition of life), social system or even the digital twin of a neural network. Creating an integral twin of the Earth in the form of its Digital Twin is obviously beyond reality. At the same time, it is clear that existing Digital Earth implementations - in particular Google Earth - have enormous heuristic possibilities.

It becomes possible to explain the crisis through a semiotic interpretation of the Digital Twin concept. There are two possible approaches to its realization: creating a Digital Earth 1) with the help of sign systems, and 2) as a sensually perceived, unsigned image of the environment. Attempting to make a copy of the entire planet using signs is impossible. At the same time, creating a visual, sign-less model of the Earth, such as Google Earth, is feasible - a task that has already been accomplished and is yielding impressive results in many applications. Accordingly, Digital Earth, in terms of the second approach, is not so much a "digital" model of the Earth as an unsigned environment modelled by digital technology.

Moreover, Digital Twin as a declaration is more comprehensive than its particular case Digital Twin of Earth. Consequently, one can reject the exclusivity of Digital Earth and turn it only into a chapter of Digital Twin. On the other hand, a critical discussion of the Digital Twin concept seems very promising. It allows to set the limits of digitalization and consequently, restore the most favourable Earth modelling regime. The unclear relationship between the two concepts leads to two possible directions of development. According to the first one, Digital Earth is a metaphor for the digitalization, which other similar metaphors could replace: e.g. Digital Ecosystem (DE), or Destination Earth (DE) [13]. According to another option, Digital Earth is a uniquely heuristic geospatial approach and is far more than "digital" realm of nowadays. For example, it can be seen as a Human Super-sense - a source of holistic, not stipulated perception of the situation [14].

The ambiguity of the terms Digital Earth and digital twin is confusing. Thus a clear delimitation of the boundary between both terms would be an important step towards a scientific definition of the Digital Earth and its development.

\subsection{Sustainable development and the Digital Earth}

The concept of sustainable development is one of the fundamental global initiatives of our time perhaps the most fundamental. Sustainable development has been defined by UN as "development that meets the needs of the present without compromising the ability of future generations to meet their own needs" [15]. ISDE is deeply connected to the implementation of sustainable development as classified through the 17 Sustainable Development Goals (SDG); the need and relevance of ensuring effective governance through the Digital Earth is evident [16].

Sustainable development is perceived as a magic cure for modern civilization, capable of eliminating the problems it faces without changing the foundations of modern society. In general it can be said that the concept of sustainable development is still waiting to be conceptualized. 
Digital Earth as a global decision-support environment, is an obvious and non-alternative tool for sustainable development. Only the Digital Earth can, through its ability to seamlessly integrate data regardless of their scale and projection, eliminate the fragmentation of governance tiers - one of the most important sources of inappropriate and misguided governance.

However, the Digital Earth still needs to be harmonized with sustainable development and the optimal functionality to ensure global governance. The solution to this problem will depend directly on the resolution of a paramount issue: the establishment of a mutually acceptable definition of the Digital Earth and the development of its theoretical foundations.

\subsection{Digital Earth and the study of the COVID-19 pandemic. Responding to global challenges}

Natural disasters and environmental degradation are serious problems of our time, undermining our faith in the possibility of sustainable human development. Digital Earth, as a decision-support environment, is actively involved in their prevention and mitigation [17]. The tremendous capabilities of the Digital Earth to collect and process data about unpredictable events were clearly exposed by the COVID-19 pandemic [18]. For the first time, the pandemic dynamics were recorded with unprecedented accuracy, providing new insights into its nature [19]. Spatio-temporal analysis of pandemics using a Digital Earth, conducted in an integrated manner without artificial partitioning into scale-dependent replicas, could provide a new tool for the analysis of ecological factors [20].

\section{Conclusions}

The year 2020 has demonstrated that the Digital Earth is widely recognized worldwide as a new scientific paradigm and a vital approach to ensuring the harmonious development of humankind in the context of sustainable development goals (SDG). The massive recognition of and interest in Digital Earth is particularly evident at the 8th Digital Earth Summit 2020. It is essential to provide a comprehensive definition of Digital Earth, unveil the scientific and technological foundations of Digital Earth, and implement them in the Digital Earth Vision 2030.

However, the task of satisfactorily describing the Digital Earth phenomenon and the resulting geospatial revolution is difficult because it involves fundamental aspects of the subject's perception of the external world, as well as deep-rooted patterns in our unconscious.

On the other hand, the Digital Earth is becoming an effective and versatile tool for the study and verification of scientific theories in various disciplines. Moreover, beyond its academic significance, the Digital Earth is a powerful approach for global governance because of its ability to integrate spatial information regardless of scale and projection. As such, the Digital Earth is actively engaged in addressing unprecedented civilizational challenges - such as the COVID-19 pandemic. Overall, a simultaneous exploration of the fundamentals of the Digital Earth and implementing it into global governance is a crucial, fruitful and urgent task.

\section{Acknowledgements}

Research was supported by RSF grant \#20-47-01001. We sincerely thank everyone who helps to made the $8^{\text {th }}$ Digital Earth Summit a success despite all the obstacles of 2020: ISDE President Alessandro Annoni, Honorary President Huadong Guo, ISDE Secretariat and especially Changlin Wang and Liu Zhen, all ISDE Bureau and Council members, and all ISDE members and friends as well. Our sincere thanks to Paris Lodron University of Salzburg (Austria) and especially to Prof. Josef Strobl and his team for their engagement and invaluable assistance.

\section{References}


[1] Max Craglia, Kees de Bie, Davina Jackson, Martino Pesaresi, Gábor Remetey-Fülöpp, Changlin Wang, Alessandro Annoni, Ling Bian, Fred Campbell, Manfred Ehlers, John van Genderen, Michael Goodchild, Huadong Guo, Anthony Lewis, Richard Simpson, Andrew Skidmore \& Peter Woodgate, "Digital Earth 2020: towards the vision for the next decade." International Journal of Digital Earth, 5:1(2012) , 4-21. doi: 10.1080/17538947.2011.638500.

[2] The 8th Digital Earth Summit Successfully Held Online. URL: http://www.digitalearthisde.org/show-48-36-1.html.

[3] The 8th Digital Earth Summit. URL: https://desummit2020.org.

[4] A. Gore, Earth in the Balance: Ecology and the Human Spirit. New York: Houghton Mifflin Harcourt. 1992. pp. 357.

[5] A. Gore, The Digital Earth: Understanding our planet in the 21st Century. Al Gorespeech at California Science Center, Los Angeles, California, on January 31, 1998.

[6] What is Digital Earth. URL: http://www.digitalearth-isde.org/list-90-1.html.

[7] Irving M. Copi, Carl Cohen, Kenneth McMahon. Introduction to Logic. 2014. Pearson Education Limited. p. 640.

[8] E. Eremchenko, What is and What is not the Digital Earth? CEUR-WS. 2744 (2020): 1-11.

[9] D.H. Gelernter, Mirror worlds, or, The day software puts the universe in a shoebox-- : how it will happen and what it will mean. New York : Oxford University Press, 1991.

[10] M. Grieves, Virtually Intelligent Product Systems: Digital and Physical Twins, in Complex Systems Engineering: Theory and Practice, S. Flumerfelt, et al., Editors. 2019, American Institute of Aeronautics and Astronautics. p. 175-200.

[11] J. van Genderen et al. Digital Earth Challenges and Future Trends. In: Guo H., Goodchild M.F., Annoni A. (eds) Manual of Digital Earth. Springer, Singapore. 2020. doi: 10.1007/978-981-329915-3_26.

[12] M. Batty. Digital twins. Environment and Planning B: Urban Analytics and City Science. 2018, 45(5):817-820. doi:10.1177/2399808318796416.

[13] S. Nativi, P. Mazzetti, M. Craglia. Digital Ecosystems for Developing Digital Twins of the Earth: The Destination Earth Case. Remote Sensing. 2021, 13(11):2119. doi: 10.3390/rs13112119.

[14] R. Simpson, Digital Earth: the next paradigm. 2020, IOP Conf. Ser.: Earth Environ. Sci. 509 012052.

[15] The Sustainable Development Agenda. URL: https://www.un.org/sustainabledevelopment/development-agenda/.

[16] Big Earth Data in Support of the SDG. URL: https://www.fmprc.gov.cn/mfa_eng/topics_665678/2030kcxfzyc/P020200927650108183958.pdf.

[17] M. Konecny et al. (2020) Digital Earth for Disaster Mitigation. In: Guo H., Goodchild M.F., Annoni A. (eds) Manual of Digital Earth. Springer, Singapore. Doi: 10.1007/978-981-32-99153_15.

[18] Chaowei Yang, Dexuan Sha, Qian Liu, Yun Li, Hai Lan, Weihe Wendy Guan, Tao Hu, Zhenlong Li, Zhiran Zhang, John Hoot Thompson, Zifu Wang, David Wong, Shiyang Ruan, Manzhu Yu, Douglas Richardson, Luyao Zhang, Ruizhi Hou, You Zhou, Cheng Zhong, Yifei Tian, Fayez Beaini, Kyla Carte, Colin Flynn, Wei Liu, Dieter Pfoser, Shuming Bao, Mei Li, Haoyuan Zhang, Chunbo Liu, Jie Jiang, Shihong Du, Liang Zhao, Mingyue Lu, Lin Li, Huan Zhou \& Andrew Ding (2020) Taking the pulse of COVID-19: a spatiotemporal perspective, International Journal of Digital Earth, 13:10, 1186-1211, doi: 10.1080/17538947.2020.1809723.

[19] A. Del Mastro, F. Monaco, E. Eremchenko, A. Nelson. Digital Health Earth: towards a global healthcare management geolocating human health condition by means of space technology. Geocontext. 8, 1 (Jan. 2021), pp. 52-71. doi: 10.30987/2686-8326-2020-52-71.

[20] E. Eremchenko, V. Tikunov, S. Vylegzhanin, A. Fetishev. Infectious Dynamics in Urban 3DEnvironment: Challenges and Possibilities. 2020. CEUR-WS. Vol. 2744. Paper48-1 - paper48-12. doi: 10.51130/graphicon-2020-2-3-48. 